\title{
Constant Cutting Force Control for CNC Machining Using Dynamic Characteristic-Based Fuzzy Controller
}

\author{
Hengli Liu, Taiyong Wang, and Dong Wang \\ Department of Mechanical Engineering, Tianjin University, Weijin Road, Tianjin 300072, China \\ Correspondence should be addressed to Hengli Liu; 1hl669@163.com
}

Received 14 November 2014; Revised 26 December 2014; Accepted 26 December 2014

Academic Editor: Vadim V. Silberschmidt

Copyright ( 2015 Hengli Liu et al. This is an open access article distributed under the Creative Commons Attribution License, which permits unrestricted use, distribution, and reproduction in any medium, provided the original work is properly cited.

\begin{abstract}
This paper presents a dynamic characteristic-based fuzzy adaptive control algorithm (DCbFACA) to avoid the influence of cutting force changing rapidly on the machining stability and precision. The cutting force is indirectly obtained in real time by monitoring and extraction of the motorized spindle current, the feed speed is fuzzy adjusted online, and the current was used as a feedback to control cutting force and maintain the machining process stable. Different from the traditional fuzzy control methods using the experience-based control rules, and according to the complex nonlinear characteristics of CNC machining, the power bond graph method is implemented to describe the dynamic characteristics of process, and then the appropriate variation relations are achieved between current and feed speed, and the control rules are optimized and established based on it. The numerical results indicated that DCbFACA can make the CNC machining process more stable and improve the machining precision.
\end{abstract}

\section{Introduction}

The cutting force is considered as the main influence factors in the machining process due to its direct influence on the machining state and the role it plays in the machining accuracy as well as the lifespan of the cutting tools. So a lot of work related to the constant cutting force control has been researched in the field of manufacturing industry [1-3].

Regarding the constant cutting force control, an adaptive cutting force controller for the milling process was proposed and the cutting forces of $x-, y$-, and $z$-axes were measured indirectly from the use of currents drawn by feed-drive servo motors in [1]. It is shown that the cutting force signals measured indirectly can be used in the adaptive controller for cutting force regulation. In fact, the feed motor current of a machine tool contains substantial information and can be used to estimate the cutting state $[4,5]$. The design and implementation of fuzzy logic-based torque control system embedded in CNC were presented in $[6,7]$. The control system adjusted the feed rate and spindle speed simultaneously as needed to regulate the cutting torque for stabling the milling processes. Artificial neural adaptive control strategy was proposed to control the cutting force in high speed end milling operations in [8], in which a reliable, robust neural controller was presented aiming at adaptively adjusting the spindle speed to prevent excessive tool wear and maintain the constant surface roughness of the work piece. A combination of neural networks, fuzzy logic, and offline optimization strategy methods was used in machining for off-line optimization and adaptive adjustment of cutting parameters in [9-12], and the combined system is an adaptive control system controlling the cutting force and maintaining the constant roughness of the surface being milled by digital adaptation of the cutting parameters. Nevertheless, a greytheory algorithm was introduced into the fuzzy controller to achieve constant cutting force control for turning systems and this design of the grey prediction fuzzy controller can not only simplify the fuzzy controller design, but also achieved the desired result in [13]. Optimizer for canonical machining commands has been developed and fuzzy adaptive control was used to keep a constant cutting load by adjusting feed rate automatically to the cutting conditions in [14].

It can be concluded that the adaptive cutting force control based on the fuzzy logic algorithm is the direction of research and development; however, the application of fuzzy logic control still needs considerable effort to identify the appropriate membership functions and fuzzy rules, particularly when the system is complicated or rapidly changing. 
The fuzzy rules for the control of the wire electrical discharge machining process were formulated and incorporated with pulse trains analysis and experience to control cutting force and power consumption in [15], and conventional control method was presented to adjust the feed rate, control the spindle load, and optimize the machining process online in [16]. A dynamic threshold-based fuzzy adaptive control algorithm was proposed to online-adjust the cut depth and cup wheel swing speed that affect the motorized spindle current for avoiding scratches on the work piece in hard sphere grinding in [17]. However, the creation of the rules base was taken from the expert operator and the experience data cannot reflect the actual machining process. So the design of the fuzzy controller presents difficulties in finding control rules and selecting an appropriate membership function. To solve this problem, a grey-theory algorithm was introduced into the turning fuzzy control to predict the next output error of the system and the error change for eliminating these difficulties in [13]. But the predicted parameter change trend is not the real trend, and lower accuracy. A hybrid selforganizing fuzzy and radial basis function neural-network controller (HSFRBNC) was developed in [18], which used a radial basis function neural-network (RBFN) to regulate the parameters of the self-organizing fuzzy controller in real time to appropriate values, instead of these values gained by the experimental tests or by trial and error. But inference between input and output is formed based on the neural network and cannot reflect the real situation because of the limited data of the fitted relationship, and lower reliability. Much work has been done on the cutting force adaptive control based on the fuzzy logic algorithm. But the control rule base is mostly established on the expert knowledge, prediction, and experimental data, not considering or simplifying the system dynamic characteristic and thus affecting the control effect and machining precision.

This paper presents a dynamic characteristic-based fuzzy adaptive control algorithm for overcoming the defect of the experience-based control rule and stabling the machining process. The research on the relation between the cutting force and the motor current $[5,19,20]$ proved that the change of the spindle motor current value reflects the cutting force well and the cutting force obtained by measuring the spindle motor current is reasonable and feasible. Therefore this paper selects the spindle motor current instead of cutting force as the condition monitoring parameters. The feed speed changes as the system adjustment parameters, the current as decision parameters to compose the feedback control loop of the feed-drive system, which to realize the cutting force adaptive control ultimately.

\section{System Structure}

Figure 1 shows the overall structure of the fuzzy cutting force control system. The control system requires current error and current change as the inputs. The output of the system is the command for feed speed adjustment. FLC stand for the fuzzy controller, CNC_Mach is CNC which is controlled, $I$ is the actual current value, and $I_{\text {ref }}$ is reference current value. At any

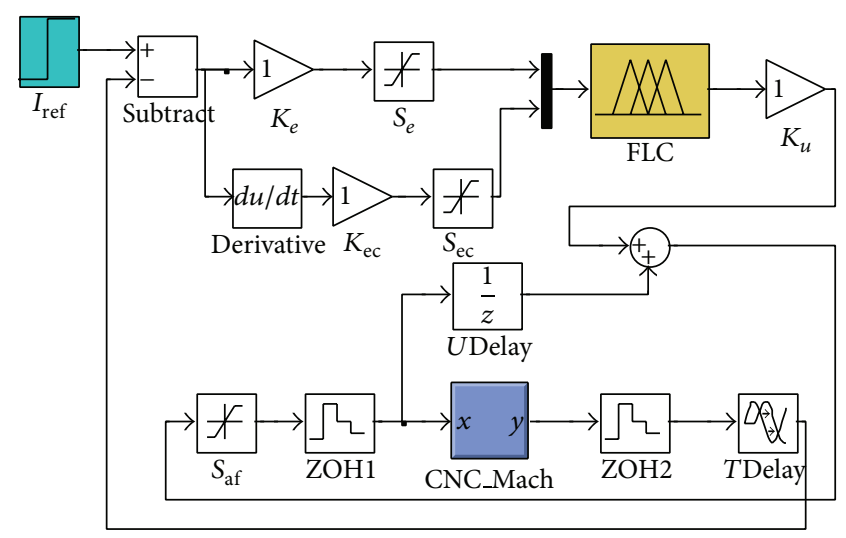

FIGURE 1: Structure of the fuzzy cutting force control system.

sampling period, the feed speed in the CNC could be written as

$$
a_{f}^{i+1}=a_{f}^{i}+\Delta a_{f}^{i+1} \quad i=0,1,2, \ldots, n,
$$

where $a_{f}^{0}=a_{f}^{\text {Init }}$ is the initial given speed. The feed speed is adaptively adjusted by the adjusting of $\Delta a_{f}$ real time in the fuzzy controller and the current quickly returned to nearby reference value to ensure the cutting force under control and machining stability. Considering the nonlinear dynamic characteristic of CNC machining process, the fuzzy control rules are achieved based on the input and output parameters dynamic model. It improves the controller performance and maintains the constant cutting force during machining comparing to the conventional methods.

\section{Machining Process Dynamic}

With the development of CNC machining technology, at present, the multiaxis linkage has become the focus and development trend. In this paper, only the $x$-axis drive motion was taken as an example of CNC machine tool based on our own research, and the established method of dynamic cutting model and its characteristics are researched, but it has the versatility to multiaxis system. The $\mathrm{CNC}$ machining system diagram is shown in Figure 2. The connection between the $x$-axis motor and ball screw is coupling and drives the workbench movement through the gear reduction. Spindle motor is connected with the spindle (tool rest) based on the synchronous belt.

3.1. Bond Graph Model. Based on the bond graph modeling technology and the power transmission interrelated lines between the components, the respective bond graph model of the main drive and $x$-axis system is established firstly and then, according to the system power flow and the causal relationship between the variables, adopts the regularization steps and makes the shaft inertia between the transmission transfer to the various subsystems and the subsystem elastic concentrate to the drive shaft and finally couples system model. Considering the resistance, capacitance, and inertia effect, the spindle and $x$-axis cutting system dynamic 

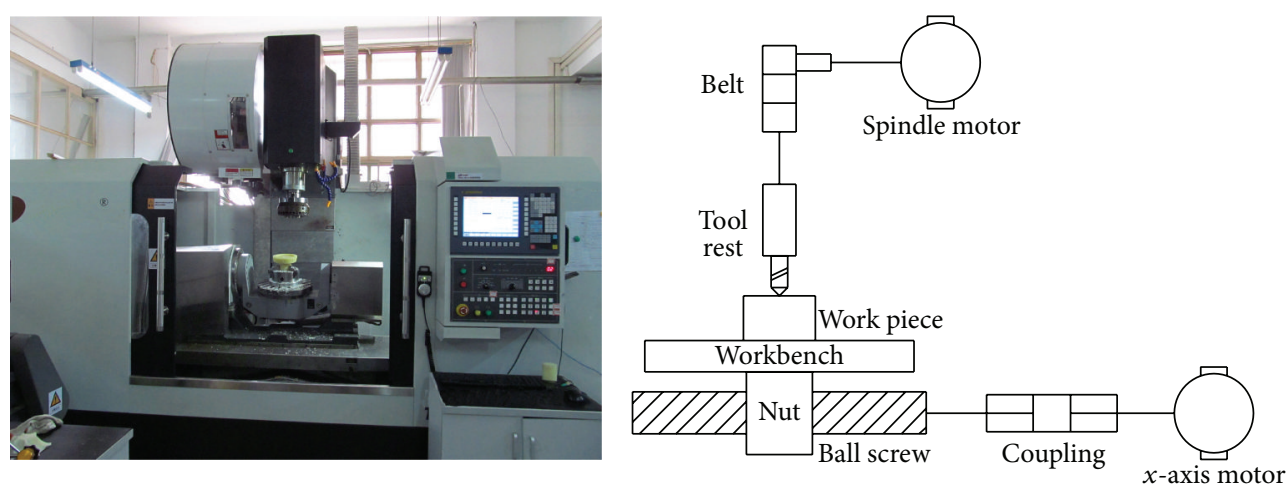

FIGURE 2: Spindle and $x$-axis system structure diagram of CNC.
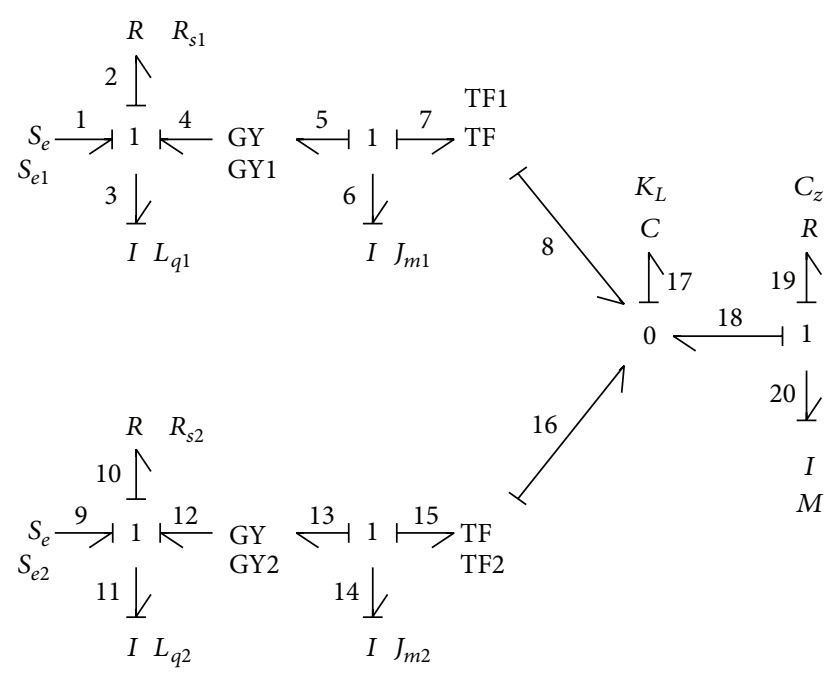

FIGURE 3: Dynamic bond graph model.

bond graph model is shown in Figure 3. The spindle motor armature inductor $L_{q 1}$ is modeled by inertia component, the resistance $R_{s 1}$, and the armature modeled by resistive component and gyroscope GY. The equation of the GY is

$$
\begin{aligned}
& e_{1}=r_{s} f_{2} \\
& e_{2}=r_{s} f_{1},
\end{aligned}
$$

where $r_{s}$ is the armature coefficient. The same as the $x$-axis motor. The mechanical drive part, the transform function of screw nut is modeled by converter $\mathrm{TF}$ and gets the translational part quality $M$, equivalent compressive stiffness $K_{L}$, and viscous damping $C_{z}$, which is the friction between the ball screw and guide rail.

3.2. Mathematical Model. The mathematical model of bond graph theory is state equation. When the state variable and the basic components of the system were determined, the state equations could be listed based on the certain rules of the bond graph model. The bonding constitutive and structural equation of the capacitance and inertia component is as follows.
For the $C$ component,

$$
\begin{gathered}
e_{17}=k_{L} q_{17} \\
f_{17}=q_{17} .
\end{gathered}
$$

For the I component,

$$
\begin{aligned}
& f_{3}=\frac{p_{3}}{L_{q 1}} \quad e_{3}=p_{3} \\
& f_{6}=\frac{p_{6}}{J_{m 1}} \quad e_{6}=p_{6} \\
& f_{11}=\frac{p_{11}}{L_{q 2}}
\end{aligned}
$$

As shown in Figure 3, the relationship among the state variables is achieved according to the causal relationship and the power flow direction of the bond graph theory, and the state equations could then be listed as follows:

$$
\begin{aligned}
& \dot{p_{3}}=e_{3}=e_{1}-e_{2}-e_{4}=S_{e 1}-\frac{R_{s 1}}{L_{q 1}} p_{3}-\frac{r_{s}}{J_{m 1}} \\
& \dot{p_{7}}=\frac{r_{s}}{L_{q 1}} p_{3}-m_{s} K_{L} q_{9} \\
& \dot{p_{11}}=S_{e 2}-\frac{R_{s 2}}{L_{q 2}} p_{11}-\frac{r_{x}}{J_{m 2}} p_{14} \\
& \dot{p_{14}}=\frac{r_{x}}{L_{q 2}} p_{11}-m_{x} K_{L} q_{17} \\
& \dot{q_{17}}=f_{17}=\frac{m_{s}}{J_{m 1}} p_{6}+\frac{m_{x}}{J_{m 2}} p_{14}-\frac{1}{M} p_{20} \\
& \dot{p_{20}}=K_{L} p_{17}-\frac{C_{z}}{M} p_{20} .
\end{aligned}
$$


TABLE 1: Parameters of simulation system model.

\begin{tabular}{lcc}
\hline Name & Symbol & Value \\
\hline Spindle/ $x$-axis motor rated voltage & $S_{e 1} / S_{e 2}$ & $380 / 220 \mathrm{~V}$ \\
Spindle $x$-axis motor resistance coefficient & $R_{s 1} / R_{s 2}$ & $0.132 / 0.15 \Omega$ \\
Spindle $/ x$-axis motor inductor & $L_{q 1} / L_{q 2}$ & $88 / 85 \mathrm{mH}$ \\
Spindle $x$-axis drive armature coefficient & $r_{s} / r_{x}$ & $9.68 / 0.0561$ \\
Spindle $x$-axis drive moment of inertia & $J_{m 1} / J_{m 2}$ & $0.0048 / 0.0063 \mathrm{~kg} \cdot \mathrm{m}^{2}$ \\
Spindle $x$-axis drive conversion coefficient & $m_{s} / m_{x}$ & $0.021 / 0.014 \mathrm{~m}$ \\
Equivalent compressive stiffness & $K_{L}$ & $37 \mathrm{MN} / \mathrm{m}$ \\
Translational part quality & $M$ & $1100 \mathrm{~kg}$ \\
Viscous damping & $C_{z}$ & $18 \mathrm{KN} \cdot \mathrm{S} / \mathrm{m}$ \\
\hline
\end{tabular}

TABLE 2: The numerical relations between the input and output.

\begin{tabular}{|c|c|c|c|c|c|}
\hline $\begin{array}{l}\text { Time } \\
\text { (s) }\end{array}$ & $\begin{array}{c}\text { Current } \\
\text { (A) }\end{array}$ & $\begin{array}{c}\text { Current error } \\
E(\mathrm{~A})\end{array}$ & $\begin{array}{c}\text { Current change } \\
\text { EC }(\mathrm{A} / \mathrm{s})\end{array}$ & $\begin{array}{r}\text { Feed speed } \\
(\mathrm{mm} / \mathrm{min})\end{array}$ & $\begin{array}{l}\text { Speed change } \\
U(\mathrm{~mm} / \mathrm{min})\end{array}$ \\
\hline 0.05 & -11.5 & -11.5 & 230 & 100 & 100 \\
\hline 0.1 & -3 & 8.5 & 400 & 450 & 350 \\
\hline 0.15 & 10 & 13 & 90 & 500 & 50 \\
\hline 0.2 & 10.5 & 0.5 & -250 & 550 & 50 \\
\hline 0.25 & -1 & 11.5 & -240 & 720 & 170 \\
\hline 0.3 & -0.5 & 0.5 & 240 & 1100 & 380 \\
\hline 0.35 & 5 & 5.5 & 100 & 1300 & 200 \\
\hline 0.4 & 13.5 & 8.5 & 60 & 1400 & 100 \\
\hline 0.45 & 6 & -7.5 & -320 & 1420 & 20 \\
\hline
\end{tabular}

3.3. Dynamic Characteristic. The spindle and the $x$-axis motor and other parameters are summarized in Table 1 of the five-axis CNC machining platform researched and developed independently.

Based on the state equation and related parameters, the bond graph model of the spindle and the $x$-axis CNC machining system simulated and the system parameters dynamic characteristic are shown in Figure 4, in which the spindle motor current and the feed speed change are taken as the input and the output, respectively. It can be observed from the numerical results that it spends about $3 \mathrm{~s}$ to get steady and more quickly response. The velocity of the load is $1440 \mathrm{~mm} / \mathrm{min}$, and the spindle motor current is $12 \mathrm{~A}$.

\section{Fuzzy Adaptive Control Algorithm}

4.1. Input and Output Parameters Relation. The inputs to the FLC are the spindle current error $E$ and spindle current change EC. The output is the feed speed change $U$. The target of reference current value $I_{\text {ref }}$ has to be predetermined and the monitored current $I$ obtained from the CNC machine. The comparison of $I$ and $I_{\text {ref }}$ leads to the two required input values at any sampling period $i$ :

$$
\begin{gathered}
E(i)=I_{\text {ref }}-I(i) \\
\mathrm{EC}(i)=E(i)-E(i-1) .
\end{gathered}
$$

It can be concluded from Figure 4 that the current fluctuates drastically while the feed speed is not the case. In
TABLE 3: The fuzzy quantization relations between the input and output.

\begin{tabular}{llllccc}
\hline Current error $E$ & NM & PS & PS & PM & PM & PB \\
Current change EC & NB & PS & PM & PS & PB & NM \\
Speed change $U$ & NB & PS & PM & PS & PM & PS \\
\hline
\end{tabular}

order to define the relationship between the input and output parameters better or the inference from the input space to the output space, the comparison simulation of the current and the feed speed is performed as shown in Figure 5. The numerical relation is listed in Table 2 .

4.2. Control Rules Generation. To provide enough rule coverage, seven fuzzy sets are used for both the inputs and outputs of the controller. The universe of discourse of all the inputs and outputs is $[-6,6]$. The triangular membership functions are used for inputs (both current error and current change) and outputs, which can be seen from Figure 6.

Based on the linguistic variables describing the fuzzy control theory, the above numerical in Table 2 is represented by NB, NM, NS, 0, PS, PM, and PB. Then the fuzzy quantization relation between the current error, current change, and speed change is obtained as shown in Table 3.

Combining with the fuzzy quantization relations in Table 3 and the results in Figure 5, the experience-based fuzzy control rules are optimized and the new rules are generated 

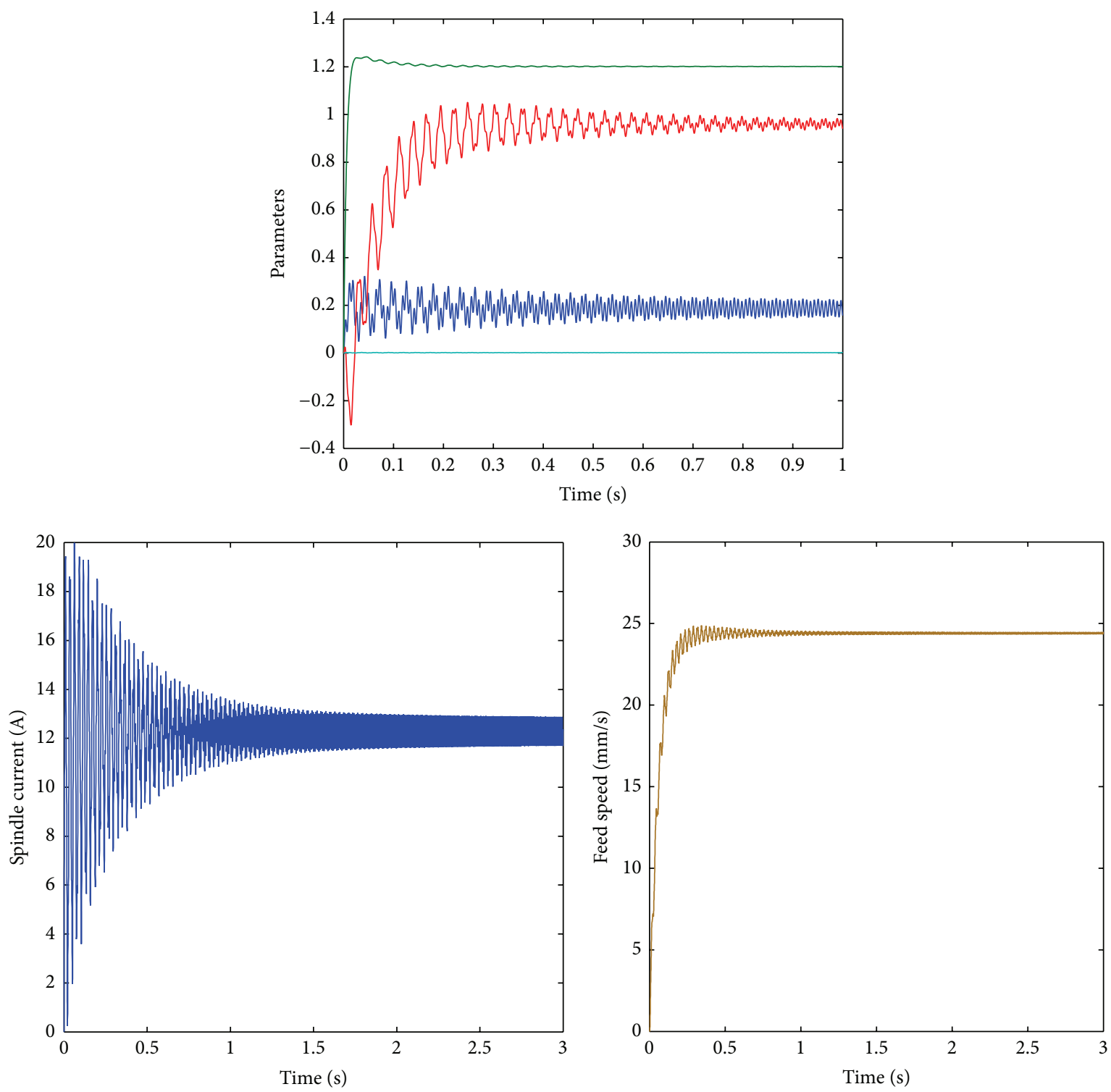

FIgURE 4: The simulation curve of spindle and $x$-axis CNC machining system.

on the basis of the system dynamic characteristic. The 49 control rules are summarized in Table 4 .

4.3. System Output. The center-of-gravity defuzzification is adopted to achieve the feed speed adjustment:

$$
U=\Delta a_{f}=\frac{\left(\sum_{i=1}^{n} \Delta a_{f i} H_{i}\right)}{\sum_{i=1}^{n} H_{i}},
$$

where $\Delta a_{f i}$ is the value associated with rule $i, H_{i}$ is the membership associated with rule $i$, and $n$ is the total number of rules. According to Section 2, $U$ was taken as the system adjustment parameters, maintaining the machining current to reference value and cutting force constant during machining.

\section{Results and Discussion}

The proposed dynamic characteristic-based fuzzy adaptive control algorithm was validated in Figure 7. The step signal was used to represent the spindle motor current change at a certain time, and the reference current is set up to $25 \mathrm{~A}$, the feed speed to $1500 \mathrm{~mm} / \mathrm{min}$, and then the quantification factors $k e, k e c$, and $k u$ are defined as $6 / 25,3 / 25$, and 250 , respectively. The different control effect is shown obviously based on the experience and the optimized control rules. When the current is mutating, it can be adjusted to the reference value at $30 \mathrm{~s}$ early based on the optimized control rules and small fluctuation. So the cutting force is controlled as soon as possible, the fuzzy controller performance is improved, and the machine is avoided from the larger impact. 
TABLE 4: The dynamic characteristic-based control rules.

\begin{tabular}{|c|c|c|c|c|c|c|c|}
\hline \multirow{3}{*}{$E$} & \multicolumn{7}{|c|}{$U$} \\
\hline & & & & EC & & & \\
\hline & NB & NM & NS & 0 & PS & $\mathrm{PM}$ & $\mathrm{PB}$ \\
\hline NB & NB & NB & NB & $\mathrm{NM}$ & $\mathrm{NM}$ & NS & NS \\
\hline NM & NB & NB & $\mathrm{NM}$ & $\mathrm{NM}$ & NS & 0 & PS \\
\hline NS & NB & NM & NM & NS & 0 & PS & $\mathrm{PM}$ \\
\hline 0 & $\mathrm{NM}$ & NM & NS & 0 & PS & PS & $\mathrm{PM}$ \\
\hline PS & NM & NS & 0 & PS & PS & $\mathrm{PM}$ & $\mathrm{PM}$ \\
\hline $\mathrm{PM}$ & NS & 0 & PS & PS & PS & $\mathrm{PM}$ & $\mathrm{PM}$ \\
\hline $\mathrm{PB}$ & 0 & PS & PS & PS & PS & $\mathrm{PM}$ & $\mathrm{PB}$ \\
\hline
\end{tabular}

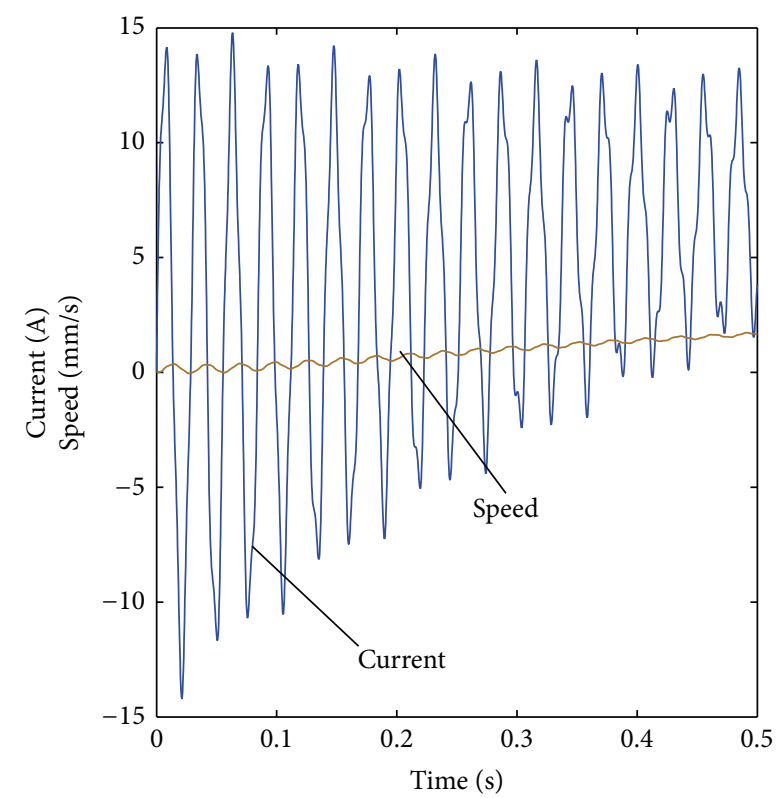

FIGURE 5: The comparison simulation curve of current and feed speed.

And based on the algorithm, the actual values range of the current deviation was $E=[-25,25]$, and the actual values range of the deviation change rate was $\mathrm{EC}=[-50,50]$. The fuzzy control program running results are shown in Table 5. There are two lines generated respectively based on the experience rule and dynamic optimization rules. It concludes that when the current and the current deviation change, the output has larger change based on the experience rule more than dynamic optimization rules, and this is consistent with the dynamic model of input and output studied in Section 3. And when the current deviation is $25 \mathrm{~A}$, deviation rate is $50 \mathrm{~A}$, and the feed rate change value is $1500 \mathrm{~mm} / \mathrm{min}$, in line with the fuzzy rules. Analyzing practically, when current increases suddenly, the cutting force increases too, and the feed speed changes also as the system adjustment through the fuzzy control, and then it makes current as soon as possible return to the reference value. So it ensures the cutting force maintains constant, reduces machine tool impact, and enhances machining stability.

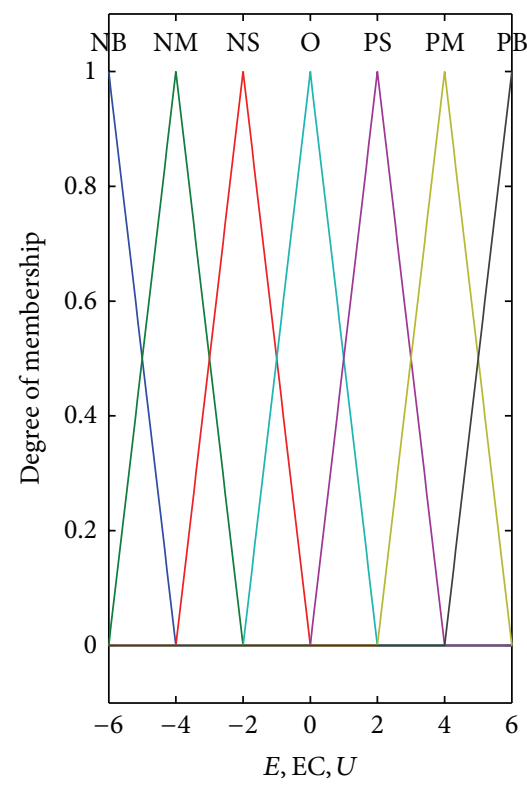

FIgURE 6: Membership function graphics.

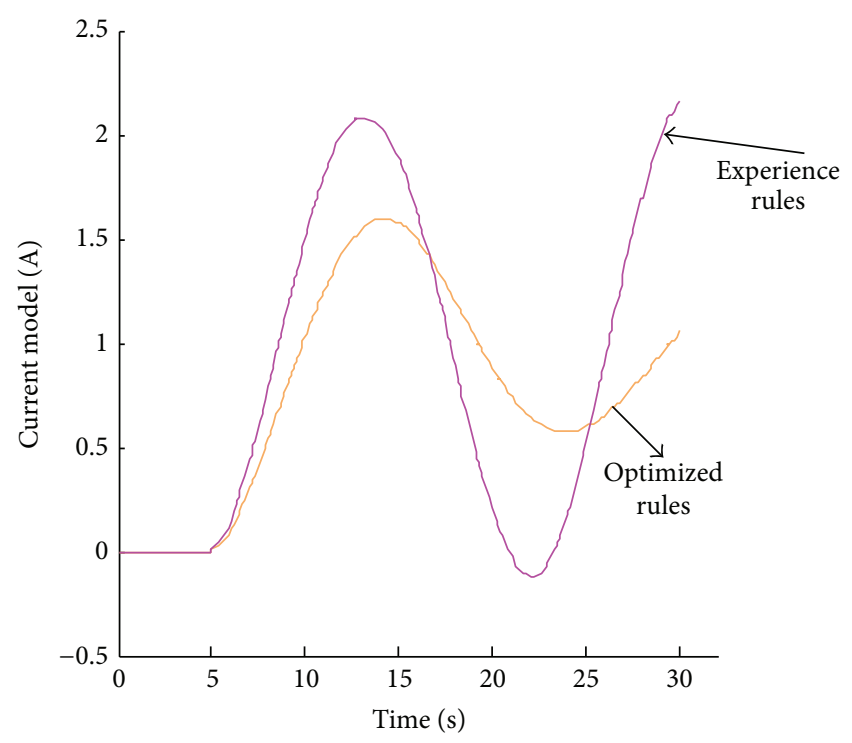

FIGURE 7: The control effect comparison graphics.

\section{Conclusions}

This paper presents an effective optimization and creation method of fuzzy control rules for the fuzzy adaptive control of cutting force in CNC machining. First, the power bond graph was employed to obtain dynamic characteristic in the CNC machining process, and the dynamic change relation of input and output linguistic variable in the fuzzy controller was obtained, which could ensure the relation in the real cutting condition. Then the reasoning is determined from the input space to the output space, based on which the experienced control rules are optimized compared with the conventional control scheme, and the DCbFACA in this paper could improve the fuzzy controller performance and 
TABLE 5: The fuzzy control program running results.

\begin{tabular}{|c|c|c|c|c|c|c|c|c|}
\hline \multirow{3}{*}{$E$} & \multicolumn{8}{|c|}{$U$} \\
\hline & \multicolumn{8}{|c|}{ EC } \\
\hline & -50 & -32 & -16 & 0 & 16 & 21 & 32 & 50 \\
\hline \multirow{2}{*}{-25} & -1500 & -1500 & -1025 & -1025 & -1025 & \multirow{2}{*}{-550} & -550 & -550 \\
\hline & -1500 & -1500 & -1500 & -1025 & -1025 & & -550 & -550 \\
\hline \multirow{2}{*}{-16} & -1500 & -1025 & -1025 & -1025 & -550 & \multirow{2}{*}{0} & 0 & 550 \\
\hline & -1500 & -150 & -1025 & -1025 & -550 & & 0 & 550 \\
\hline \multirow{2}{*}{-8} & -1025 & -1025 & -550 & -550 & 0 & \multirow{2}{*}{550} & 550 & 1025 \\
\hline & -1500 & -1025 & -1025 & -550 & 0 & & 550 & 1025 \\
\hline \multirow{2}{*}{0} & -1025 & -550 & -550 & 0 & 550 & \multirow{2}{*}{550} & 550 & 1025 \\
\hline & -1025 & -1025 & -550 & 0 & 550 & & 550 & 1025 \\
\hline \multirow{2}{*}{1} & -1025 & -550 & -450 & 115 & 550 & 550 & 550 & 1025 \\
\hline & -1025 & -550 & -450 & 91 & 540 & 540 & 550 & 1000 \\
\hline \multirow{2}{*}{8} & -1025 & -550 & 0 & 550 & 1025 & 1025 & 1025 & 1500 \\
\hline & -1025 & -550 & 0 & 540 & 540 & 990 & 1025 & 1025 \\
\hline \multirow{2}{*}{16} & -550 & 0 & 550 & 1025 & 1025 & \multirow{2}{*}{1025} & 1500 & 1500 \\
\hline & -550 & 0 & 550 & 550 & 550 & & 1025 & 1025 \\
\hline \multirow{2}{*}{25} & 0 & 550 & 1025 & 1025 & 1025 & \multirow{2}{*}{1025} & 1500 & 1500 \\
\hline & 0 & 550 & 550 & 550 & 550 & & 1025 & 1500 \\
\hline
\end{tabular}

control the constant cutting force and the machining stability better. Finally, the efficiency and feasibility of the DCbFACA was validated by the simulation.

\section{Conflict of Interests}

The authors declare that there is no conflict of interests regarding the publication of this paper.

\section{Acknowledgments}

This research was sponsored by the National Natural Science Foundation of China under Grant 51475324 and the Natural Science Foundation of Tianjin under Grant 13JCZDJC34000. The authors gratefully acknowledge the assistance of $\mathrm{Mr}$. Zhang Pan and Mr. Liu Jigan in the machining experiment.

\section{References}

[1] T.-Y. Kim and J. Kim, "Adaptive cutting force control for a machining center by using indirect cutting force measurements," International Journal of Machine Tools and Manufacture, vol. 36, no. 8, pp. 925-937, 1996.

[2] C. Y. Xu and Y. C. Shin, "Control of cutting force for creepfeed grinding processes using a multi-level fuzzy controller," Transactions of the ASME-Journal of Dynamic Systems, vol.129, no. 4, pp. 480-492, 2007.

[3] D. Kim and D. Jeon, "Fuzzy-logic control of cutting forces in $\mathrm{CNC}$ milling processes using motor currents as indirect force sensors," Precision Engineering, vol. 35, no. 1, pp. 143-152, 2011.

[4] G. D. Kim and C. N. Chu, "Indirect cutting force measurement considering frictional behaviour in a machining centre using feed motor current," The International Journal of Advanced Manufacturing Technology, vol. 15, no. 7, pp. 478-484, 1999.
[5] Y.-H. Jeong and D.-W. Cho, "Estimating cutting force from rotating and stationary feed motor currents on a milling machine," International Journal of Machine Tools and Manufacture, vol. 42, no. 14, pp. 1559-1566, 2002.

[6] M. Liang, T. Yeap, A. Hermansyah, and S. Rahmati, "Fuzzy control of spindle torque for industrial CNC machining," International Journal of Machine Tools \& Manufacture, vol. 43, no. 14, pp. 1497-1508, 2003.

[7] R. Haber-Guerra, S. Y. Liang, J. R. Alique, and R. HaberHaber, "Fuzzy control of spindle torque in high-speed milling processes," Journal of Manufacturing Science and Engineering, vol. 128, no. 4, pp. 1014-1018, 2006.

[8] U. Zuperl, F. Cus, and M. Reibenschuh, "Neural control strategy of constant cutting force system in end milling," Robotics and Computer-Integrated Manufacturing, vol. 27, no. 3, pp. 485-493, 2011.

[9] U. Zuperl, "A combined system for off-line optimization and adaptive adjustment of the cutting parameters during a ball-end milling process," Journal of Mechanical Engineering, vol. 51, no. 9, pp. 542-559, 2005.

[10] U. Zuperl, F. Cus, and M. Reibenschuh, "Modeling and adaptive force control of milling by using artificial techniques," Journal of Intelligent Manufacturing, vol. 23, no. 5, pp. 1805-1815, 2012.

[11] U. Zuperl and F. Cus, "System for off-line feedrate optimization and neural force control in end milling," International Journal of Adaptive Control and Signal Processing, vol. 26, no. 2, pp. 105123, 2012.

[12] P. Benardos and G.-C. Vosniakos, "Offline flexible optimisation of feed and speed in computer numerical control machining of sculptured surfaces exploiting dedicated cutting force metamodels," Proceedings of the Institution of Mechanical Engineers, Part B: Journal of Engineering Manufacture, vol. 228, no. 6, pp. 878-892, 2014.

[13] R.-J. Lian, B.-F. Lin, and J.-H. Huang, "A grey prediction fuzzy controller for constant cutting force in turning," International 
Journal of Machine Tools and Manufacture, vol. 45, no. 9, pp. 1047-1056, 2005.

[14] F. Ridwan, X. Xu, and F. C. L. Ho, "Adaptive execution of an NC program with feed rate optimization," International Journal of Advanced Manufacturing Technology, vol. 63, no. 9-12, pp. 11171130, 2012.

[15] Y. S. Liao and J. C. Woo, "Design of a fuzzy controller for the adaptive control of WEDM process," International Journal of Machine Tools and Manufacture, vol. 40, no. 15, pp. 2293-2307, 2000.

[16] U. Zuperl, F. Cus, and M. Milfelner, "Fuzzy control strategy for an adaptive force control in end-milling," Journal of Materials Processing Technology, vol. 164-165, pp. 1472-1478, 2005.

[17] D. Li, M. Xu, C. Wei, D. Hu, and L. Xu, "A dynamic thresholdbased fuzzy adaptive control algorithm for hard sphere grinding," The International Journal of Advanced Manufacturing Technology, vol. 60, no. 9-12, pp. 923-932, 2012.

[18] J. Lin and R.-J. Lian, "Hybrid self-organizing fuzzy and radial basis-function neural-network controller for constant cutting force in turning," The International Journal of Advanced Manufacturing Technology, vol. 53, no. 9-12, pp. 921-933, 2011.

[19] M.-Y. Yang and T.-M. Lee, "Hybrid adaptive control based on the characteristics of CNC end milling," International Journal of Machine Tools and Manufacture, vol. 42, no. 4, pp. 489-499, 2002.

[20] S.-J. Kim, H. U. Lee, and D.-W. Cho, "Prediction of chatter in NC machining based on a dynamic cutting force model for ball end milling," International Journal of Machine Tools and Manufacture, vol. 47, no. 12-13, pp. 1827-1838, 2007. 

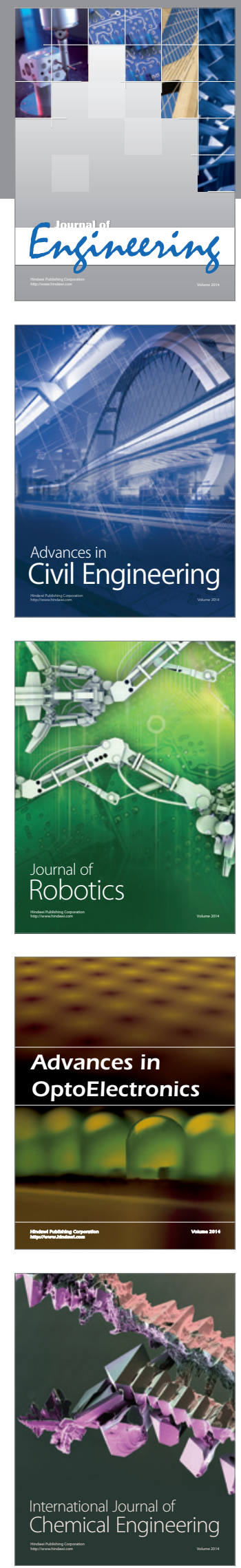

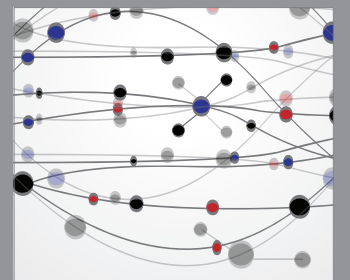

The Scientific World Journal
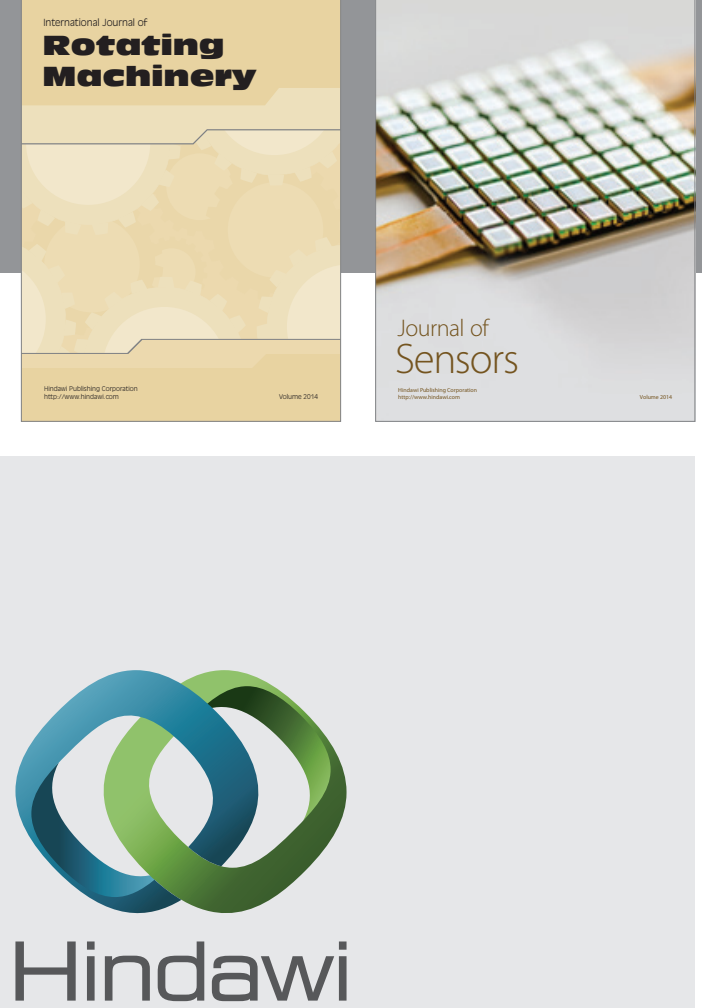

Submit your manuscripts at http://www.hindawi.com
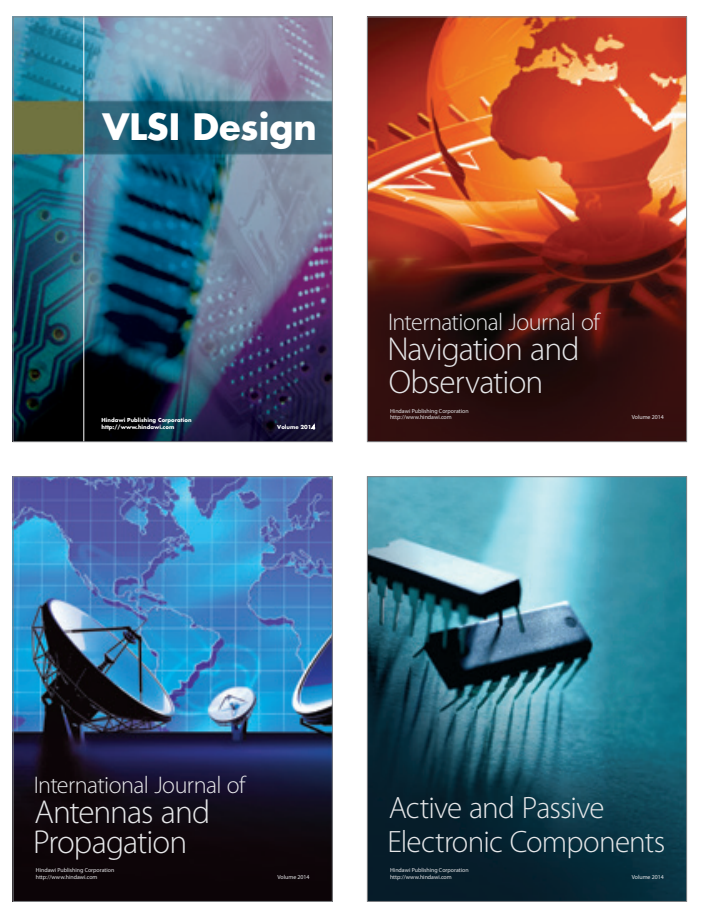
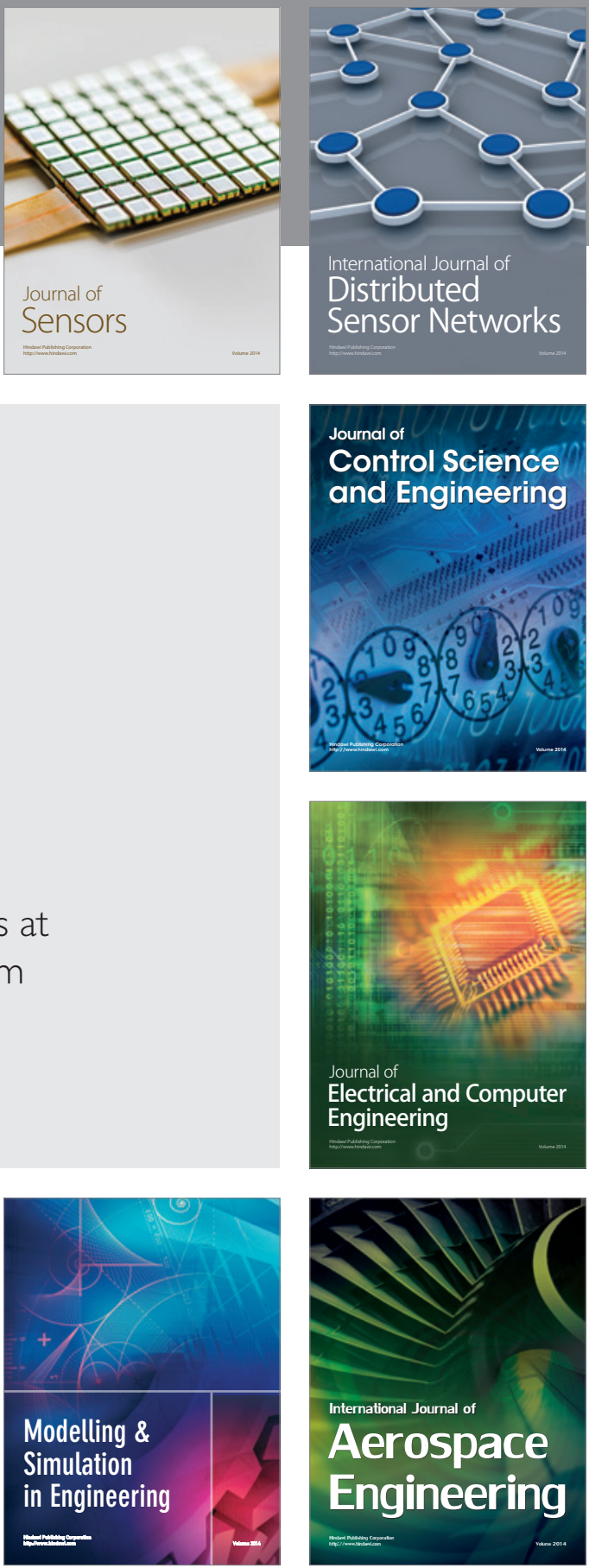

Journal of

Control Science

and Engineering
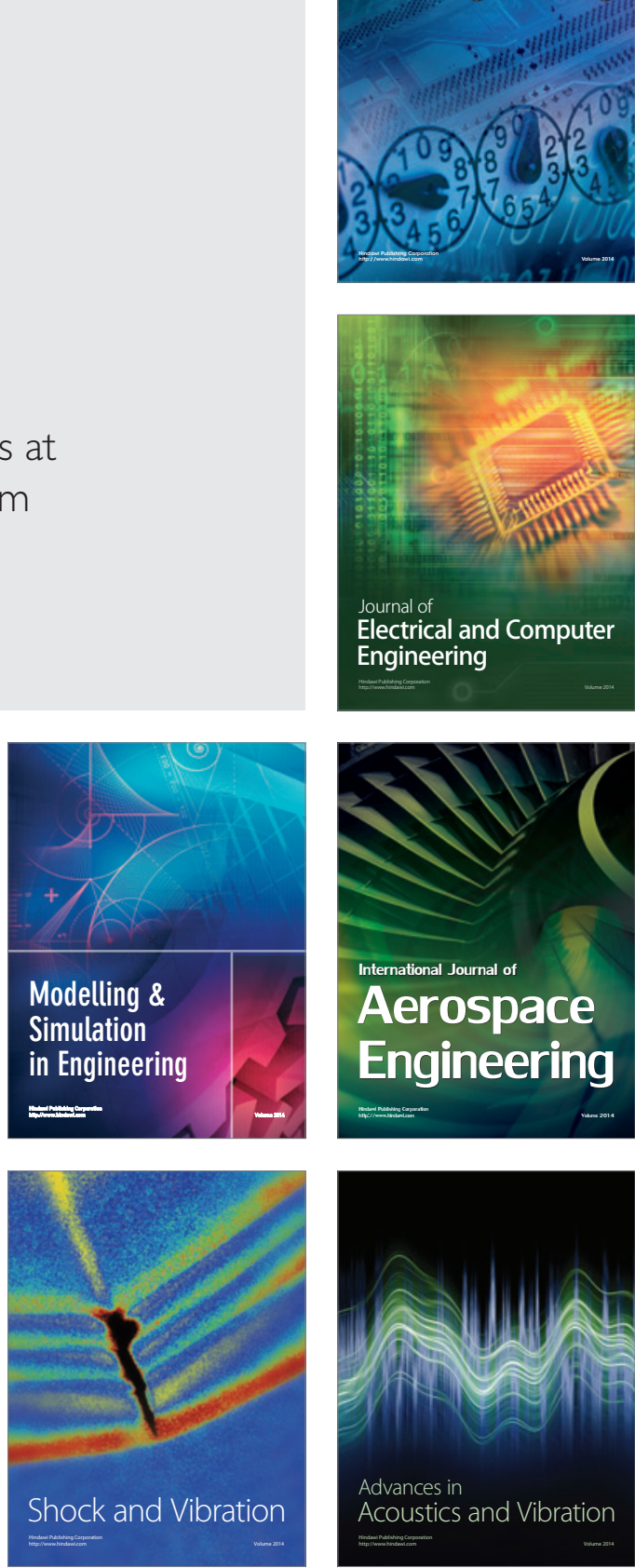